Revista de la red interuniversitaria de estudios sobre las literaturas rioplatenses contemporáneas en Francia

$18 \mid 2018$

El río y la ciudad

\title{
El río Usumacinta: confluencia de historias
}

\section{Perla Petrich}

\section{OpenEdition}

\section{Journals}

Edición electrónica

URL: http://journals.openedition.org/lirico/5577

DOI: 10.4000/lirico.5577

ISSN: 2262-8339

Editor

Réseau interuniversitaire d'étude des littératures contemporaines du Río de la Plata

Referencia electrónica

Perla Petrich, « EL Río USUMACINTA: CONFLUencia de HISTORIAS》, Cuadernos LIRICO [En línea]

18 | 2018, Puesto en línea el 08 octubre 2018, consultado el 02 mayo 2019. URL : http:// journals.openedition.org/lirico/5577; DOI : 10.4000/lirico.5577

Este documento fue generado automáticamente el 2 mayo 2019.

\section{(c) $(1) \Theta \Theta$}

Cuadernos LIRICO está distribuido bajo una Licencia Creative Commons Atribución-NoComercialSinDerivar 4.0 Internacional. 


\title{
El río Usumacinta: confluencia de historias
}

\author{
Perla Petrich
}

1 Los ríos fluyen libremente según sus propias leyes naturales, muchas veces imprevisibles, pero al mismo tiempo ese fluir está estrechamente ligado a dictámenes humanos, muchas veces también imprevisibles. De este axioma -la estrecha relación existente entre lo espacial y lo social, ya genialmente establecido y desarrollado por Braudel, podríamos deducir que es imposible o al menos inoperante, desde una perspectiva analítica, desconectar la historia fluvial de la historia de la humanidad. Esta interconexión es lo que permite explicar los cambios operados en el río con el transcurso del tiempo y concomitantemente en las sociedades que, de una u otra manera, han estado conectadas a ese universo acuático.

2 Tener en cuenta la relación histórica entre el agua y el hombre permite comprender y explicar cambios sustanciales que han convertido a ríos, antes ejes de economías florecientes, en objetos de exclusivo interés ecológico, lo cual, a su vez, ha modificado totalmente el hábitat y las formas de subsistencia de los pobladores que habitaban en sus orillas. Cómo se construye y reconstruye esta relación dinámica es lo que intentaremos analizar tomando como ejemplo el río Usumacinta.

El río Usumacinta se forma en Guatemala y desemboca en el golfo de México. Su longitud es de $1123 \mathrm{~km}$ y es el río más caudaloso y extenso de México y Centroamérica. En un tramo de 310 kilómetros este río sirve de límite fronterizo entre Guatemala y México antes de adentrarse en el Estado de Tabasco. En su paso por Tabasco se une con el río Grijalba.

4 Nuestra intención es concentrarnos en dos zonas de Tabasco atravesadas por este río. La primera corresponde al Alto Usumacinta ("zona de los ríos"): desde Guatemala hasta las cercanías de la ciudad de Tenosique en México. La segunda, denominada Bajo Usumacinta ("zona de los pantanos"), comienza a la altura de Tenosique y pasa por las ciudades tabasqueñas de Balancán de Domínguez, Emiliano Zapata y Jonuta. En este tramo, al llegar al Municipio de Centla, confluye con el río Grijalva y forma un delta conocido como "los 
pantanos de Centla". Este delta abarca unos $50 \mathrm{~km}$ de ancho por $70 \mathrm{~km}$ de largo. La ciudad más importante es Frontera, que oficia de puerto marítimo en el Golfo de México.

\section{Historia social de la zona (desde fines del siglo XIX hasta la actualidad)}

5 Entre 1870 y 1930 puede situarse el auge económico del Usumacinta con dos ciudades centrales: Tenosique, en donde vivían los "patrones", y Frontera, en donde se centraban, comercializaban y exportaban los productos: maderas (caoba) y chicle.

6 La población trabajadora se situaba en caseríos dispersos, campamentos principales ubicados a la orilla del río y campamentos menores en la selva. En los campamentos de la selva se cortaban los árboles o extraía el chicle, y en los campamentos mayores se los preparaba para el transporte por el río: los troncos se ataban unos con otros haciendo así grandes balsas que eran guiadas por remeros muy especializados hasta el puerto de Frontera.

7 Durante el período de las monterías y explotación chiclera, la población interna se desplazaba continuamente desde sus caseríos o pueblos hacia los centros urbanos para ser "enganchados" y luego partir hacia la selva. El lugar de asentamiento de la mayor parte de la población no eran las ciudades, salvo el caso de los "patrones" de empresas y comerciantes, sino la selva y las costas del Usumacinta.

8 Se consideraba a esa población como "flotante" (ellos mismos se denominaban de ese modo) porque estaba constituida por gente venida de distintas regiones de Tabasco, de Campeche y Yucatán, y porque además se desplazaban continuamente según la instalación de los campamentos.

9 En la zona de los ríos, en la época de las monterías y las chiclerías, los campamentos centrales se instalaban en la orilla pero, una vez desmantelados, con la entrada del ferrocarril y la construcción de carreteras (mediados del siglo XX, a partir de 1940), en esos lugares surgieron pueblos. Una parte de la población se radicó en ellos y otra se dispersó hacia el interior. La economía se diversificó: agricultura, ganadería, trabajo asalariado en los ingenios, en el corte de la caña de azúcar y en menor proporción la pesca. Es la gran época de peones y hacendados, pero es también la de la Reforma agraria de Lázaro Cárdenas (1930): una parte de los pobladores adquiere el carácter de ejidatarios y comienzan a explotar sus propias tierras.

10 En la zona de los pantanos, en la región del delta, la vida continuó a otro ritmo. Las poblaciones se fijaron en la orilla del río y la pesca constituyó la base económica, complementada con una agricultura y una ganadería que nunca llegó a ser intensiva.

11 A partir de 1970 se produce el gran "seísmo" provocado por la instalación en esta zona de PEMEX (Petróleos Mexicanos). Se crea entonces la ciudad Pemex, que llegó a tener más de 20.000 habitantes (actualmente unos 5.700).

12 Con el boom de la explotación petrolera, la quimera de la colonización del trópico tabasqueño incrementó un nuevo flujo migratorio, esta vez desde todos los estados mexicanos. Ya vimos que Tabasco se caracterizó por ser una región que atraía población de los estados vecinos, pero en este caso fue una verdadera explosión demográfica. Gran parte de los inmigrantes provenían de los estados de Michoacán, Veracruz, Chiapas, 
Oaxaca e incluso del Distrito Federal. En 1980 PEMEX contrata 19.000 trabajadores, de los cuales sólo el 41\% era tabasqueño, el resto provenía de otros estados.

Una consecuencia inmediata en el medio ambiente fue la contaminación debida a la explotación petrolera. El río Usumacinta sufrió el paso de grandes buques que transportaban petróleo y gas. Esta circulación incesante provocó una fuerte erosión de las costas. No sólo la "petrolización", sino también la paulatina inclusión en la "modernidad globalizada", cambiaron completamente esta región: miles de hectáreas quedaron inutilizadas para la agricultura e incluso para la ganadería a causa de las napas de petróleo. Además, la pesca mecanizada gracias a nuevas técnicas acabó en pocos años con la abundancia de casi todas las especies existentes.

La crisis de PEMEX se debió a una mala administración que creó una deuda muy importante, a lo que se sumó la caída de los precios del crudo y una gran competencia por parte de otros países petroleros. Miles de obreros quedaron en la calle. Este desastre económico no dejó ninguna salida: no había posibilidad de reintegrarse a las actividades de la selva porque no había más corte de madera ni chicle. La pesca había disminuido por causa de la contaminación, pero también por la pesca intensiva. Lo que restaba de agricultura o ganadería no era rentable por las pestes, la baja calidad de los productos o los bajos precios del mercado. Ante esta situación los foráneos regresaron a sus estados y los nativos que no poseían tierras por no ser ejidatarios debieron contratarse como peones aceptando salarios miserables.

\section{Emigración}

La emigración de los jóvenes tabasqueños fue el reflejo de esta catástrofe ecológica y sus consecuencias económico-sociales. Actualmente son los centros urbanos, sobre todo los turísticos como Cancún, los que atraen a la población en busca de trabajo. Los más necesitados u osados se lanzan hacia la aventura de Estados Unidos. Unos regresan al año con algunos dólares, otros se tardan, pero mandan remesas, y no pocos desaparecen para siempre.

16 Y no sólo los hombres abandonaron estas tierras, sino también todos los seres imaginarios que las poblaban. El territorio había estado compartido entre hombres y seres sobrenaturales (animales fantásticos, espíritus, ánimas de los muertos) con los cuales se mantenían estrechas relaciones. Esas relaciones -que constituían una geografía imaginaria- también se desarticularon cuando el río dejó de ser el eje de la vida económica. Como reflejo de la realidad (la emigración de muchos pobladores por falta de trabajo) se supuso que los "encantos" también huyeron y desaparecieron para siempre y con ellos el sentido de un mundo organizado dentro de un sistema socioeconómico estable. El orden cosmológico que mantenía la cohesión identitaria se escindió. Hoy en día ya no puede hablarse de "lagartos reyes" o de duendes o piratas o sirenas que habitaban en el río. Esos seres imaginarios van desapareciendo porque les han eliminado su hábitat (la selva se vuelve pastizal, las aguas se contaminan con petróleo, pesticidas y cuerpos de emigrantes centroamericanos en estado de putrefacción). En el límite entre Guatemala y México o en Los Altos del Usumacinta los inmigrantes centroamericanos son con frecuencia víctimas de las maras, pandillas de extrema ferocidad que los despojan de sus pertenencias, los violan, asesinan y lanzan al río.

Un habitante nos comentaba: 
Y así vamos viviendo, por aquí bastante tranquilo. Tan tranquilo que creo que en parte es por eso que ya nadie quiere quedarse, fíjese que yo creo que, hasta el Salvaje, un hombrote grande y peludo que vivía en las cuevas, hasta ése se fue para los Estados Unidos. Y lo mismo debe haber pasado con la Sirena, porque dicen que antes al mediodía cantaba siempre un gallo y era porque una sirena se bañaba. Una sirena galana ella, de pelo bien largo. Pero yo ya no escuché nada. Quizás al gallo lo mataron para comérselo, por eso se quedó mudo. Y ni Llorona tenemos de noche. Aquí los únicos que andan llorando a medianoche son los borrachos o las ánimas de esos pobres centroamericanos que tiraron al río.

18 Hay que tener en cuenta que, si bien la razón principal de la desaparición del universo imaginario ha sido el cambio del sistema económico, existen otras causas: la implantación cada vez más firme de las Iglesias protestantes, el contacto con mundos hiper-modernos como Cancún o Estados Unidos, el mayor nivel de escolarización, la influencia de la TV y sus nuevos "mitos", etc.

19 Para los que partieron, el Usumacinta es un recuerdo que comparan críticamente con su vida presente en las ciudades. Ellos se asumen como urbanos, como "hombres de la ciudad". Por el contrario, los que se quedaron se han vuelto hombres "del lugar", enraizados en los pueblos. Hombres que hablan con nostalgia del pasado e intentan, a través de discursos de gran influencia ecologista, defender el medio. En estos discursos el río Usumacinta, los pantanos y los manglares se han convertido en símbolos de una solidaridad perdida. Como consecuencia, nuevas oposiciones identitarias se han creado entre "los que se fueron" y "los que se quedaron". Entre estos últimos han surgido otras diferencias: los vecinos considerados predadores del medio, los que cazan o pescan indiscriminadamente y los que defienden el ecosistema e intentan protegerlo. Las oposiciones suelen ser también marcadas entre ejidatarios y pobladores (sin derechos a tierras ejidales); entre vaqueros, ganaderos o agricultores que han recibido ayuda de programas gubernamentales y los que han estado excluidos; entre trabajadores asalariados (en lo que queda de PEMEX, en los ingenios, en las maquiladoras) y los que viven de sus tierras, de la pesca o de jornales cotidianos. A esto se suman las diferencias que se establecen entre el origen indígena (los choles son mayoritarios) o mestizo de los pobladores oriundos.

20 Es en el vacío que han dejado los relatos tradicionales que se instala el discurso ecologista. Este discurso vehicula la idea fundamental de "salvar", de "proteger" el medio y, si es posible, de revivir las costumbres o las formas de vida "de antes". Lo transmiten tanto los pobladores pobres como los empresarios y el gobierno. Se trata de un mensaje consensual cuya intención es provocar otros tipos de comportamientos o acciones.

21 El discurso ecologista es un instrumento operacional con intenciones variables. Puede parecer homogéneo, pero la finalidad es diferente según el tipo de locutor:

22 - los pobladores de los caseríos o pueblos quieren evitar la pesca indiscriminada, el paso de lanchas de motor o barcos de gran tonelaje que erosionan las orillas, el desmonte de la selva, los basurales, la contaminación, etc.;

23 - los empresarios o el gobierno pretenden asentar las bases de nuevas actividades productivas, en este caso el turismo ecológico. 


\section{Turismo ecológico}

24

Antes el río era productor o medio de transporte de materia prima (peces, maderas preciosas, bananos, petróleo, etc.); actualmente, frente a los cambios económicos y sociales, el río se ha convertido en un producto comercializable. Se valora sólo como paisaje $y$, en tanto que tal, es un objeto que se vende turísticamente, es decir: puede visitarse, fotografiarse y ser navegado en cayac o en lanchas de motor. El río es playa para nadar y broncearse, espacio natural para extasiarse. Las ciudades y los pueblos importantes (Tenosique, Frontera) explotan esa posibilidad. El gobierno hace otro tanto con "la biosfera de los pantanos de Centla", una reserva que sirve de gran atractivo turístico y está dotada de restaurantes, lanchas para recorrer los manglares, etc. Esta reserva ecológica está paradójicamente en gran parte financiada por PEMEX, el principal contaminador de la zona.

Las múltiples actividades turísticas están justificadas con una ideología ecologista que no deja ser una manipulación económica. En este punto podríamos apoyarnos en Maurice Godelier y comprobar, como él lo postula, que toda realidad empírica, es decir, los elementos concretos que se refieren a la instalación y reproducción socio-económica, implica una representación (una idea consensual) que hace aceptable las actividades. En este caso la acción concreta es el turismo y la ideología que lo justifica es la ecología.

El "turismo ecológico" es practicado ya sea por particulares, ya sea por el mismo gobierno de Tabasco. Ambos esgrimen el slogan de "protección del medio ambiente". Sin embargo, ese turismo no protege el medio humano; es una pantalla que esconde, o al menos deja de lado, las poblaciones ribereñas que no tienen acceso a los beneficios del turismo.

Este río "ecológico" crea nuevos sectores de pobreza y, al mismo tiempo, nuevos discursos por parte de los "dejados de lado". Esos discursos pueden resultar totalmente anacrónicos, pero son, al mismo tiempo, reflejos de la situación. Uno de los tantos campesinos que entrevistamos nos lo resumió:

Como ya lo han acabado todo, la mayor parte de la gente de aquí se va para Frontera, a Villahermosa, a Cancún... Por todas partes está regada la gente. Eso porque aquí no hay nada para hacer. Aquí no podemos ser asalariados. Aquí no hay digamos "ricos" con quienes uno pueda ir a trabajar. Aquí somos todos iguales. Antes había ricos y con ellos chambeábamos nosotros. Eso cuando yo tenía quince años. Estábamos acostumbrados a eso: a pescar y a chambear con machete. Pero los ricos se murieron y ahí quedaron los hijos y ellos acabaron con todo. Así fue.

Es evidente que son las ciudades, al albergar la población -o al menos una parte de la población- con posibilidades de invertir en reconversiones económicas, quienes logran "monopolizar" el río como productor de riqueza. La población que tradicionalmente vivía del río queda excluida del "escenario" turístico o, como máximo, se incluye prestando servicios temporarios. Algunas excepciones pueden ser, por ejemplo, los pobladores que se reúnen para revivir "tradiciones" y constituyen grupos de danza o música. Pero en general el turismo no les aporta beneficios: no producen objetos artesanales (ni cerámica, ni tejidos), en sus casas precarias no pueden albergar a turistas y para el transporte sus canoas son demasiado inseguras. Tampoco pueden ofrecer el producto de la pesca, porque ya casi no existe. Sin embargo, en los restaurantes se ofrecen diariamente las "Sabrosas mojarras del Usumacinta", cuyo origen en realidad no es el río sino los viveros creados y mantenidos por los que poseen tierras y dinero para sustentar estas infraestructuras. 

incita a escenificar el río para atraer el turismo; no sólo en los Pantanos de Centla, sino también en pueblos con situaciones estratégicas como es el caso de Tapichulapa, un pueblo a la orilla del río Grijalba, el gran afluente del Usumacinta. Es un pueblo muy pintoresco, creado para el turismo. Un escenario "colonial" en donde todo ha sido edificado, pintado, retocado, ampliado para lograr el codiciado label de "Pueblo mágico" que les asegura una buena afluencia del turismo atraído por lo auténtico y antiguo.

En este caso también los contrastes son inevitables: por una parte los comerciantes, los restaurantes, uno o dos hoteles, y por otra parte una población sin trabajo. Una población que de ser indígena es requerida para los desfiles o las fiestas conmemorativas. La municipalidad guarda una buena cantidad de vestidos tradicionales que presta a los ancianos indígenas para que el día de la fiesta se exhiban por la calle. Terminada la fiesta devuelven los trajes hasta el próximo festejo patrio.

\section{Conclusión: el curso del río}

Entre tanto, el río Usumacinta sigue su curso, que puede adquirir múltiples facetas reales o imaginarias- impuestas por el hombre. El río que podemos ver hoy se ha convertido en un museo y a ese museo sólo tienen acceso los que lo financian, los que lo explotan y, por supuesto, los turistas que pagan la entrada. Estamos frente a una situación de Greenwash ("lavado verde"), es decir, ante empresas que utilizan el medioambiente con fines de marketing.

Los pobladores de las orillas ya no viven del río, sino de subvenciones del gobierno, de remesas o de lo poco que pueden obtener con trabajos de peones y, en el mejor de los casos, de empleos esporádicos dentro del marco turístico (por ejemplo como choferes o mecánicos). Esta consecuencia social y económica de la práctica ecologista es una fase casi ignorada. Lo que salta a la vista y merece la aprobación es la protección del medio ambiente, loable indiscutiblemente, pero que no va acompañada de una protección de sus habitantes.

\section{BIBLIOGRAFÍA}

Braudel Fernand, La Mediterranée. L'espace et l'histoire, Paris, Flammarion, 2009 [1977].

Botello Alfonso et al., "Migración, adaptación y costos", Alfonso Botello et al. (comps.), Vulnerabilidad de las zonas costeras mexicanas ante el cambio climático, Campeche, Gobierno del Estado de Tabasco, Semarnat, UNAM-ICMyL y Universidad Autónoma de Campeche, 2010.

Claval Paul, La géographie culturelle, París, Nathan Université, 1995.

De Vos Jan, Oro Verde. La conquista de la selva lacandona por los madereros tabasqueños, 1822-1949, México, FCE, 1988.

Cuadernos LIRICO, 18 | 2018 
Delisle Marie-Andrée, Jolin Louis, Un autre tourisme est-il possible ?, Québec, Presses universitaires du Québec, 2007.

Huet Françoise, "Le tourisme, chance ou malédiction pour les pays du Sud ?", Espace Prépas, n 118, 15 avril 2008, p. 100-104.

Lequin Marie, Écotourisme et gouvernance participative, Québec, Presses de l'Université du Québec, 2004.

Chenault Victoria, Migrantes y aventureros en la frontera sur, México, SE/CIESAS, 1989.

Fardel Eric, L'homme et la terre, París, Editions du CTHS, 1990.

Giménez Gilberto, Sectas religiosas en el sureste. Aspectos sociográficos y estadísticos, México, CIESAS, Sureste, Cuadernos de la Casa Chata 161, 1988.

Godelier Maurice, L'Idéel et le matériel. Pensée, économies, sociétés, Paris, Flammarion, 2010.

Lefebre Henri, La production del espace, París, Ed. Anthropos, 2000.

Maffesoli Michel, Le temps des tribus, París, La Table Ronde, $3^{\mathrm{e}}$ éd., 2000.

Martinez-Assad Carlos, Breve historia de Tabasco, México, Fondo de Cultura Económica, 2006.

Muñoz Práxedes, “Una visión de los hombres y mujeres de la Barra de San Pedro, Tabasco, descolonizando saberes y promoviendo acciones desde una comunidad pescadora y una antropología comprometida", Mérida- México, 70 Congreso Anual, Sociedad de Antropología Aplicada (SfAA), 24-27 de marzo de 2010.

Muñoz Práxedes, Cruz Jorge L., “Una etnografía reflexiva en dos sistemas de pesca artesanal, el río y el Golfo de México, desde identidades encontradas de pescadores en Tabasco", PueblaMéxico, $8^{\circ}$ Congreso AMER, 24-27 de mayo de 2011.

Pérez Chan, Armando, Frontera: legendario puerto marítimo y fluvial de Tabasco, México, Gobierno del estado de Tabasco, 2000.

Petrich Perla, "Tabasco voces de tierra y agua”, Mario Ruz (coord.), Paisajes de río, río de paisaje. Navegaciones por el Usumacinta, México, UNAM, 2010, p. 429-495.

Ruz Mario (coord.), Paisajes de río, río de paisaje. Navegaciones por el Usumacinta, México, UNAM, 2010.

Trujillo Bollo Mario, El golfo de México en la centuria decimonónica. Entornos geográficos, formación portuaria y configuración marítima, México, Cámara de Diputados, CIESAS-Porrúa, 2005.

Vautravers Guadalupe y Ochoa Aurora M., "Las recientes transformaciones de la migración en Tabasco", Migraciones Internacionales, vol. 5, núm. 1, México, COLEF, 2009, p. 65-91.

West, Robert C. et al., Las tierras bajas de tabasco en el sureste de México, México, Gobierno del Estado de Tabasco, Instituto de cultura de Tabasco, Villahermosa, 1985.

\section{RESÚMENES}

Este artículo se concentra en la la relación estrecha existente entre la historia fluvial y la historia social de los pobladores de las orillas. Cómo se construye y reconstruye esta relación dinámica es lo que se intenta analizar tomando como ejemplo el río Usumacinta. Un río que fue un sujeto activo en la economía de la zona y actualmente es un objeto, explotado por el turismo ecológico, sin otro valor que el de su belleza natural. 
This article adresses the close relation between the fluvial histoty and the social history of the inhabitants of its banks. We try to analyze how this dynamical relation is built and rebuilt taking as an example the Usumacinta river. This river used to play an active role in the economy of the area but now it is exploited only for ecologic tourism, without any other value than the one of its natural beauty.

Cet article est consacré à la relation étroite existant entre l'histoire d'un fleuve et l'histoire sociale des habitants de ses rives. On tente d'analyser comment cette relation dynamique se construit et se reconstruit en prenant comme exemple le fleuve Usumacinta. Ce fleuve qui a joué un rôle fondamental dans l'économie de la zone est actuellement un objet exploité pour le tourisme écologique, sans autre valeur que celle de sa beauté naturelle.

ÍNDICE

Palabras claves: río Usumacinta, Tabasco, historia, cambios, ecología, turismo Mots-clés: Fleuve Usumacinta, Tabasco, histoire, changement, écologie, tourisme Keywords: Usumacinta river, Tabasco, history, change, ecology, tourism

\section{AUTOR}

\section{PERLA PETRICH}

Université Paris 8 